\title{
Analisis Desain Tie Rod Alat Penukar Kalor Shell dan Tube Berdasarkan TEMA Standard
}

\author{
(Analysis Shell and Tube Heat Exchanger Tie Rod Design Based on TEMA Standard) \\ Krisdiyanto ${ }^{\text {a }}$, Rahmad Kuncoro Adi ${ }^{\text {b }}$ \\ ${ }^{a, b}$ Program Studi Teknik Mesin, Fakultas Teknik, Universitas Muhammadiyah Yogyakarta \\ Jl. Brawijaya, Kasihan, Bantul, Yogyakarta 55183 \\ a krisdiyanto@umy.ac.id, ${ }^{b}$ rahmad.kuncoro.2016@ft.umy.ac.id
}

\begin{abstract}
Abstrak
Heat exchanger adalah peralatan yang digunakan untuk memindahkan energi kalor tanpa disertai perpindahan massa. Perancangan heat exchanger harus memenuhi standar yang telah ditentukan. Salah satu standard yang digunakan yaitu dokumen yang dikeluarkan oleh TEMA. Standar tersebut masih belum optimal sehingga perlu dilakukan optimasi pada komponennya. Salah satu komponen heat exchanger yaitu tie rod. Komponen tersebut dianalisis menggunakan metode finite element. Simulasi pemberian tekanan pada geometri dapat dilakukan menggunakan platform SimScale. Tekanan yang dipakai sebagai beban dapat dipakai untuk menghitung von mises pada shell. Hasil penelitian ini menunjukkan nilai overdesign pada komponen tie rod yaitu 475,19\%.
\end{abstract}

Keywords: finite element, tegangan, overdesign

\begin{abstract}
Heat exchanger is an equipment that is used to transfer heat energy without mass transfer. The design of the heat exchanger must meet predetermined standards. One of the standards used is the document issued by TEMA. The standard is still not optimal so it needs to be optimized for its components. One component of the heat exchanger is tie rod. The components were analyzed using the finite element method. Simulations of applying stress to the geometry can be done using the SimScale platform. Pressure used as a load can be used to calculate von mises on the shell. The results of this study indicate the value of overdesign on the tie rod component is $475.19 \%$.
\end{abstract}

Keywords: finite element, stress, overdesign

\section{Pendahuluan}

Alat penukar kalor shell dan tube merupakan alat yang berfungsi sebagai penukar energi kalor tanpa diikuti pertukaran massa [1]. Perancangan peralatan tersebut harus sesuai dengan standar yang sudah ditentukan [2]. Salah satu standard yang digunakan dalam proses perancangan heat exchanger shell and tube yaitu dokumen yang dipublikasikan oleh Tubular Exchanger Manufacturer Association (TEMA) [3]. Peneliti melakukan modifikasi komponen tidak sesuai dengan standar untuk mendapatkan nilai terbaik dari performa dan biasa produksi [4]. Hal tersebut dilakukan oleh Mizutani dkk pada penelitiannya. Modifikasi betuk alat penukar kalor memengaruhi tegangan yang terjadi [5]. Analisis tegangan maksimal pada desain digunakan untuk melindunginya dari kegagalan [6], sedangkan analisis tegangan rata-rata digunakan untuk meningkatkan efisiensi material yang digunakan [7]. Overdesign terjadi apabila nilai tegangan rata-rata pada komponen heat exchanger tidak sama dengan tegangan izin material yang digunakan. Analisis finite element dapat digunakan untuk menyelesaikan equations untuk tegangan [8]. 


\section{Metode}

Metode finite element dalam penelitian ini membutuhkan geometri alat penukar kalor. Geometri tersebut dibuat dengan perangkat lunak Autodesk Inventor. Geometri kemudian diimpor ke dalam platform SimScale. Rancangan geometri dalam penelitian ini berdasarkan dokumen yang dipublikasikan oleh TEMA. Data rancangan geometri penelitian ini tersaji pada Tabel 1 dan bentuk 3D geometri ditunjukkan pada Gambar 1 . Rancangan geometri yang dipakai menggunakan diameter shell 273,1 mm. Diameter tersebut berada pada interval $152-381 \mathrm{~mm}$. Diameter shell pada inverval tersebut menggunakan tie rod sebanyak empat buah dengan diameter $9,5 \mathrm{~mm}$ jika berdasarkan dokumen yang dipublikasikan TEMA.

Tabel 2.1. Data rancangan geometri

\begin{tabular}{cc}
\hline Tipe & BEM (horisontal) \\
\hline Material & SS 304 \\
\hline Safety Factor & 2 \\
\hline Yield Stregth & $205 \mathrm{Mpa}$ \\
\hline Tegangan Izin & $102,5 \mathrm{Mpa}$ \\
\hline Diameter Shell & $273,1 \mathrm{~mm}$ \\
\hline Tebal Shell & $3,4 \mathrm{~mm}$ \\
\hline Diameter Tubesheet & $266,3 \mathrm{~mm}$ \\
\hline Tebal Tubesheet & $19,1 \mathrm{~mm}$ \\
\hline Tipe Baffle & Segmental \\
\hline Baffle cut & $25 \%$ \\
\hline Jumlah Baffle & 2 \\
\hline Jumlah Tie Rod & 4 \\
\hline Diameter Tie Rod & $9,5 \mathrm{~mm}$ \\
\hline Diameter Tube & $19,05 \mathrm{~mm}$ \\
\hline Tebal Tube & $0,5 \mathrm{~mm}$ \\
\hline Jumlah Tube & 64 \\
\hline Internal Pressure (shell) & $0,36 \mathrm{MPa}$ \\
\hline
\end{tabular}

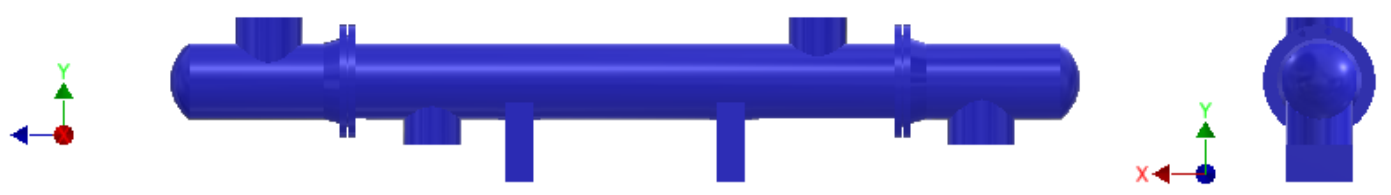

Gambar 2.1. Geometri alat penukar kalor

Hasil simulasi Von mises di shell dibandingkan dengan tegangan hasil perhitungan menggunakan persamaan 1 [9]. Perhitungan tersebut digunakan untuk memastikan apakah hasil simulasi tersebut akurat [10]. Tingkat penyimpangan yang diperbolehkan yaitu sebesar $5 \%$ [11].

$$
\sigma_{v m}=\sqrt{\sigma_{H}^{2}-\sigma_{H} \cdot \sigma_{L}+\sigma_{L}^{2}}
$$

Keterangan:

$\sigma_{H} \quad$ : Longitudinal stress (MPa)

$\sigma_{H} \quad$ : Hoop stress (MPa)

Longitudinal stress dapat dihitung dengan persamaan 2 dan Hoop stress dapat dihitung dengan persamaan 3 [9].

$$
\begin{aligned}
& \sigma_{L}=\frac{p \cdot d}{4 t} \\
& \sigma_{H}=\frac{p \cdot d}{2 t} \\
& \text { Keterangan: } \\
& \quad \mathrm{P} \quad: \text { Internal Pressure (MPa) }
\end{aligned}
$$


d : Diameter dalam shell $(\mathrm{m})$

t : Tebal shell $(\mathrm{m})$

Hasil simulasi yang akurat kemudian dipakai untuk menghitung nilai overdesign tie rod. Perhitungan tersebut menggunakan persamaan 4 [12].

$\%$ Overdesign $=\frac{\left|\sigma_{i z i n}-\sigma_{\text {average }}\right|}{\sigma_{\text {average }}}$

Keterangan:

$\sigma_{i j i n} \quad$ : Tegangan izin $(\mathrm{Pa})$

$\sigma_{\text {average }}$ : Tegangan rata-rata $(\mathrm{Pa})$

\section{HASIL DAN PEMBAHASAN}

Hasil simulasi pemberian tekanan pada geometri menggunakan platform SimScale berupa distribusi tegangan pada shell ditampilkan pada Gambar 2 dan tie rod pada Gambar 3. Tegangan pada shell dibandingkan dengan nilai tegangan hasil perhitungan yang menggunakan persamaan 1 . Hasil perhitungan tegangan dengan menggunakan persamaan 1 nilainya $12,2 \mathrm{MPa}$ dan tegangan hasil simulasi sebesar $11,94 \mathrm{MPa}$. Penyimpangan hasil simulasi sebesar 2,14 \%. Hasil tersebut masih berada di bawah batas yang sudah ditentukan yaitu $5 \%$.

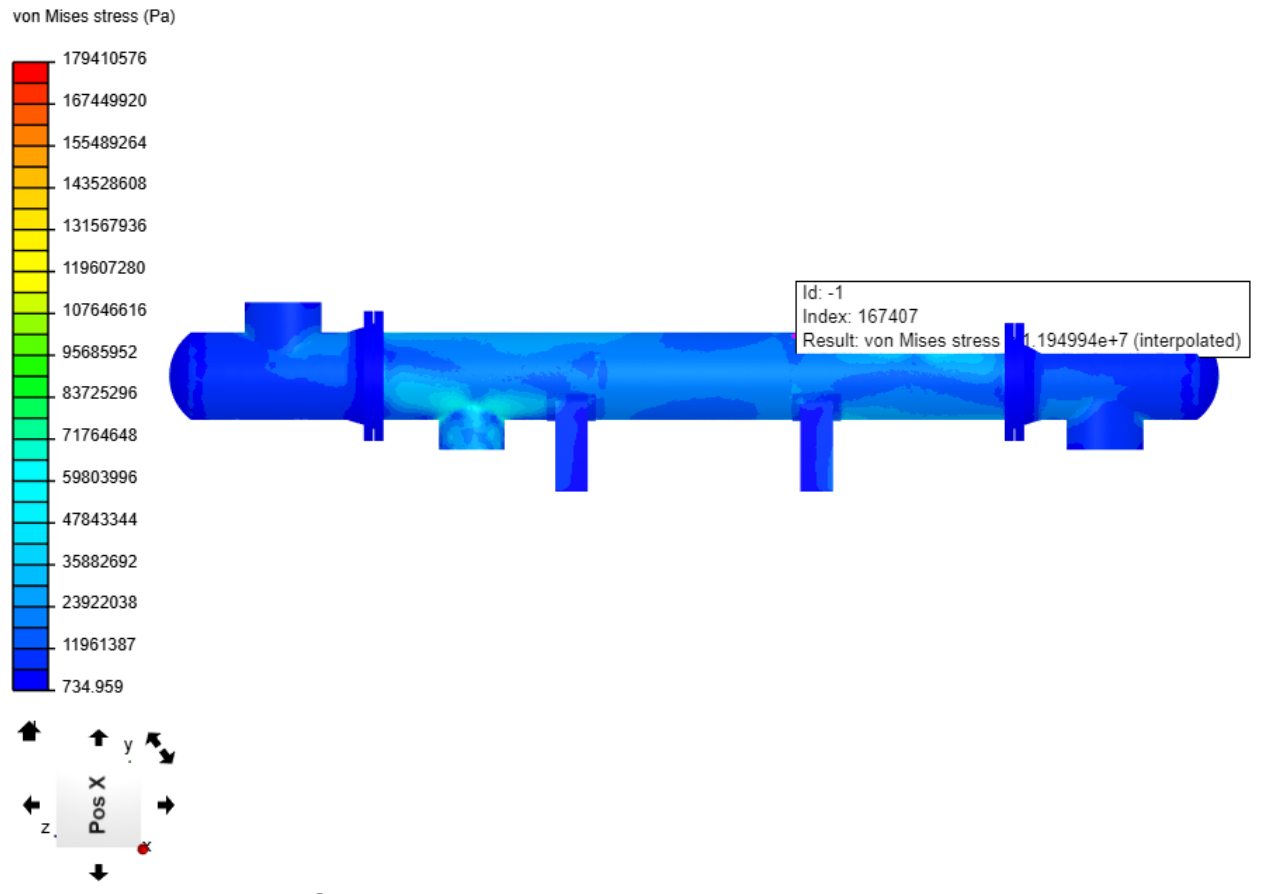

Gambar 3.1. Distribusi tegangan pada shell 


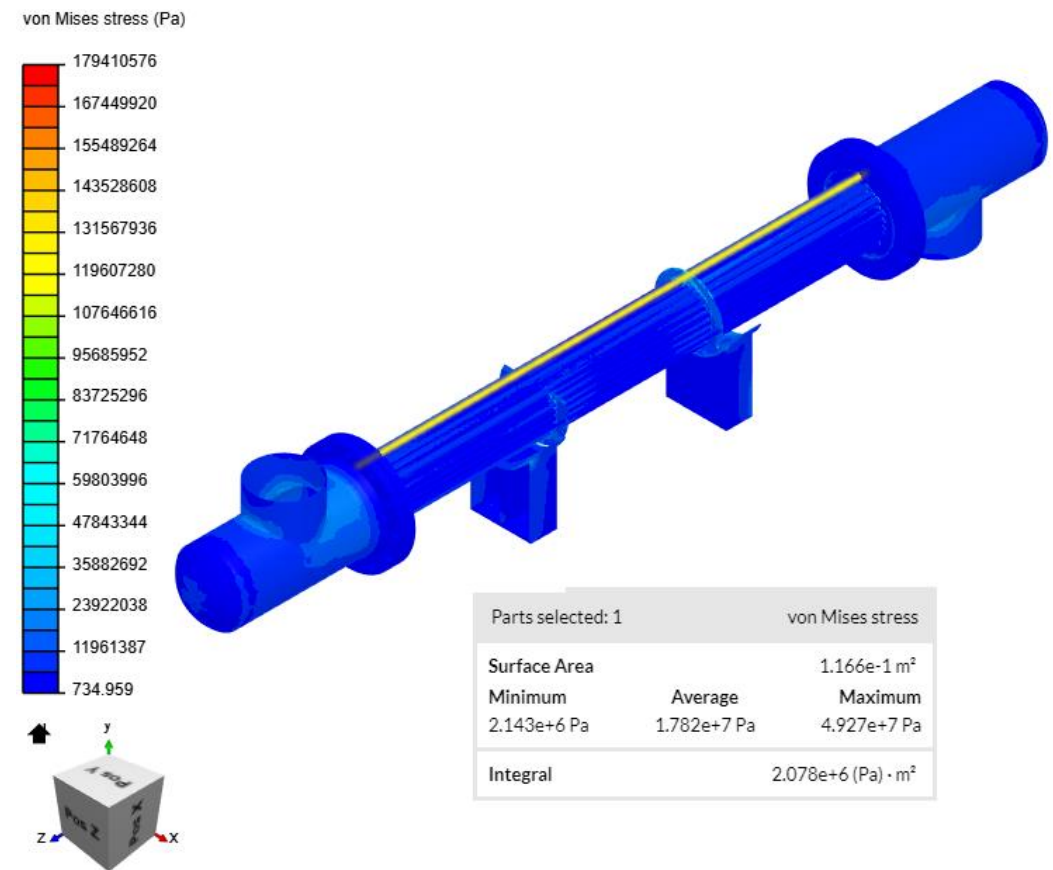

Gambar 3.2. Tegangan rata-rata pada tie rod

Rata-rata tegangan pada tie rod sebesar 17,82 MPa. Tegangan tersebut dipakai untuk menghitung overdesign yang terjadi. Perhitungan overdesign menggunakan persamaan 4. Nilai overdesign pada tie rod tersebut sebesar $475,19 \%$.

Standar yang dipublikasikan oleh TEMA masih kurang optimal jika dilihat dari nilai perpindahan kalor pada peralatan alat penukar kalor [4]. Maka dari itu, optimalisasi perlu dilakukan secara komprehensif. Selain itu, optimalisasi perpindahan kalor parameter lain seperti tegangan akan lebih baik jika dimasukan dalam proses optimalisasi.

\section{Kesimpulan}

Desain tie rod pada alat penukar kalor berdasarkan dokumen yang dipublikasikan oleh TEMA memerlukan optimalisasi jika dilihat dari nilai tegangan ratarata pada komponen tersebut. Penelitian ini menggunakan diameter shell sebesar 273,1 $\mathrm{mm}$. Diameter tersebut berada pada interval $152 \mathrm{~mm}-381 \mathrm{~mm}$. Diameter shell yang berada pada interval tersebut menggunakan tie rod sebanyak empat buah dengan diameter 9,5 mm. Overdesign pada geometri tersebut sebesar 475,19\%.

\section{Daftar Pustaka}

[1] D. P. Sekulic, "A reconsideration of the definition of a heat exchanger," Int. J. Heat Mass Transf., vol. 33, no. 12, pp. 2748-2750, 1990, doi: 10.1016/00179310(90)90209-D.

[2] K. D. Shirode, D. S. Rane, and M. Y. Naik, "Comparison of Design and Analysis of Tubesheet Thickness by Using UHX Code of ASME and TEMA Standard," pp. 96108, 2013.

[3] E. Ozden and I. Tari, "Shell side CFD analysis of a small shell-and-tube heat exchanger," Energy Convers. Manag., vol. 51, no. 5, pp. 1004-1014, 2010, doi: 10.1016/j.enconman.2009.12.003.

[4] F. T. Mizutani, F. L. P. Pessoa, E. M. Queiroz, S. Hauan, and I. E. Grossmann, "Mathematical programming model for heat-exchanger network synthesis including detailed heat-exchanger designs. 2. Network synthesis," Ind. Eng. Chem. Res., vol. 42, no. 17, pp. 4019-4027, 2003, doi: 10.1021/ie020965m. 
[5] S. Xu and W. Wang, "Numerical investigation on weld residual stresses in tube to tube sheet joint of a heat exchanger," Int. J. Press. Vessel. Pip., vol. 101, pp. 37-44, 2013, doi: 10.1016/j.ijpvp.2012.10.004.

[6] James R. Farr and M. H. Jawad, Guidebook for the Design of ASME Section VIII Pressure Vessel Second Edition, vol. 53, no. 9. 2013.

[7] Q. Liang, Performance-Based Optimization of Structures: Theory and Applications. 2007.

[8] L. Yang, C. Weinberger, and Y. T. Shah, "Finite element analysis on horizontal vessels with saddle supports," Comput. Struct., vol. 52, no. 3, pp. 387-395, 1994, doi: 10.1016/0045-7949(94)90224-0.

[9] Khurmi.R.S and Gupta.J.K, A Textbook of Machine design, no. I. 2005.

[10] W. L. Oberkampf, T. G. Trucano, and C. Hirsch, "Verification, validation, and predictive capability in computational engineering and physics," Appl. Mech. Rev., vol. 57, no. 1-6, pp. 345-384, 2004, doi: 10.1115/1.1767847.

[11] H. Franck and D. Franck, Forensic engineering fundamentals. 2012.

[12] W. A. Beyers, A. Zapke, and G. Venter, "Improved Cover Type Header Box Design Procedure," no. December, 2015. 